\title{
The roles of testicular nuclear receptor 4 (TR4) in male fertility-priapism and sexual behavior defects in TR4 knockout mice
}

\author{
Loretta L Collins ${ }^{1 \dagger}$, Yi-Fen Lee ${ }^{1 \dagger}$, Huei-Ju Ting ${ }^{1}$, Wen-Jye Lin', Ning-Chun Liu', Charles K Meshul', Hideo Uno ${ }^{3}$, \\ Bo-Ying Bao ${ }^{1,4}$, Yen-Ta Chen ${ }^{1,5}$ and Chawnshang Chang ${ }^{1,4^{*}}$
}

\begin{abstract}
Background: Successful reproductive efforts require the establishment of a situation favorable for reproduction that requires integration of both behavior and internal physiological events. TR4 nuclear receptor is known to be involved in male fertility via controlling spermatogenesis, yet its roles in regulating other biological events related to reproduction have not been completely revealed.
\end{abstract}

Methods: Male TR4 knockout (TR4-/-) and wild type mice were used for the sexual behavior and penile dysfunction studies. Mice were sacrificed for histological examination and corresponding genes profiles were analyzed by quantitative RT-PCR. Reporter gene assays were performed.

Results: We describe an unexpected finding of priapism in TR4-/- mice. As a transcriptional factor, we demonstrated that TR4 transcriptionally modulates a key enzyme regulating penis erection and neuronal nitric oxide synthese NOS (nNOS). Thereby, elimination of TR4 results in nNOS reduction in both mRNA and protein levels, consequently may lead to erectile dysfunction. In addition, male TR4-/- mice display defects in sexual and social behavior, with increased fear or anxiety, as well as reduced mounting, intromission, and ejaculation.

Reduction of ER alpha, ER beta, and oxytocin in the hypothalamus may contribute to defects in sexual behavior and stress response.

Conclusions: Together, these results provide in vivo evidence of important TR4 roles in penile physiology, as well as in male sexual behavior. In conjunction with previous finding, TR4 represents a key factor that controls male fertility via regulating behavior and internal physiological events.

Keywords: TR4, priapism, sexual behavior

\section{Background}

Members of the nuclear receptor superfamily are known to play important roles in differentiation, development, homeostasis, and metabolism, as well as in disease development and progression [1]. As a member of the nuclear receptor superfamily with several known regulatory targets [2], Testicular nuclear receptor 4 (TR4) may affect many signaling pathways and thus have a major impact on physiological functions [2]. Creation of

\footnotetext{
* Correspondence: chang@urmc.rochester.edu

+ Contributed equally

${ }^{1}$ George Whipple Lab for Cancer Research, Departments of Pathology, Urology, Radiation Oncology, and The Cancer Center, University of Rochester Medical Center, Rochester, NY 14642, USA

Full list of author information is available at the end of the article
}

mammalian gene knockout models has become a successful strategy to study the physiological roles of orphan receptors in vivo $[3,4]$. As a nuclear receptor with wide tissue distribution [5-10] and a relative mystery with respect to physiological function, TR4 was a good candidate for analysis using a knockout mouse model. A complex set of phenotypic abnormalities were found to exist in the TR4 knockout $\left(\mathrm{TR}_{4}{ }^{-1}\right)$ mouse, including significant growth retardation [11], defects in female reproductive function [12] and maternal behavior [11], impaired cerebella function [13,14], and reduced myelination [15]. In addition, recent studies found that TR4 might be a master regulator controlling glucose 
and lipid metabolism [16-18] as well as foam cell formation [19].

Our previous study revealed that TR4 expresses predominantly in the testis in a stage-dependent manner and deletion of TR4 in male mice reduced sperm production and disrupted spermatogenesis, thereby impaired male fertility [20]. Successful reproductive efforts require the establishment of a situation favorable for reproduction that requires integration of both behavior and internal physiological events. Following continue studies of TR4's roles in male reproduction, we describe an unexpected finding of priapism in some $\mathrm{TR} 4^{-/-}$mice. Penile priapism, or persistent erection, is characterized by trapped blood within the corpus cavernosa, which leads to reduced tissue oxygenation, increased blood viscosity, disruption of tissue elasticity, fibrosis, and finally irreversible failure to achive erection $[21,22]$. It is a significant urologic emergency that can lead to irreversible loss of erectile function if not promptly resolved. It has been linked to sickle cell disease as well as the use of vasoactive drugs, yet its molecular mechanism remains unclear. The etiology of this disorder is obscure. The cyclic nucleotide second messenger cGMP generated by activated guanylyl cyclase in penile smooth muscle cells regulates penile erection. These includes activation of guanylyl cyclase requires nitric oxide $(\mathrm{NO})$, release in the penis upon sexual stimulation from neuronal and endothelial sources containing NO synthase (NOS), and respectively termed nNOS and eNOS. The crucial role of NOS in mediating erectile function was further supported by the finding that the mice lacking the gene for eNOS, nNOS, or both have a tendency for priapic activity [23]. To our surprise, in the mice with TR4 knockout [11], penile priapism was one of the most striking phenotypes observed.

In characterizing the fertility defects, in addition to partial penile priapism among $\mathrm{TR} 4^{-/-}$males, we also found that TR $4^{-1-}$ mice displayed delayed sexual maturity, reduced sperm production [20], priapism, and abnormal sexual behavior, all of which contribute to significant reduction of TR4 ${ }^{-1-}$ male fertility. Furthermore, the expressions of nNOS, enzyme involved in production of the erectile mediator NO, were reduced in penis tissue from TR4-knockout mice, where a transcriptional regulation of nNOS by TR4 was also presented.

\section{Methods}

\section{Experimental animals and genotyping}

$\mathrm{TR}^{-/-}$mice were produced as described [11], and housed in the vivarium facility of the University of Rochester Medical Center. The animals were provided a standard diet with constant access to food and water, and exposed to a 12-hour light/dark cycle. All experimental protocols were approved by the University Committee on Animal Resources and the office of Environmental Health and Safety prior to implementation.

Genotyping was carried out as described [11]. Briefly, genomic DNA was isolated from mouse tail samples and used as template for polymerase chain reaction (PCR). Primers for amplification of the wildtype and targeted alleles are TR4-107 (wildtype, forward): 5'-GGAGACACACTGCACATGTTCGAATAC-3', TR4-111 (wildtype, reverse): 5'-CACAGCTCATTTCTCTGCTCACTTACTC-3', Neo3a (targeted allele, forward): 5'-GCAGCGCATCGCCTTCTATC-3', and TR4-34 (targeted allele, reverse): 5'TGCAAGCATACTTCTTGTTCC-3'.

\section{Tissue preparation, histology, and immunostaining}

Mice were anesthetized with an overdose of pentobarbital and perfused through the left ventricle with $20 \mathrm{ml}$

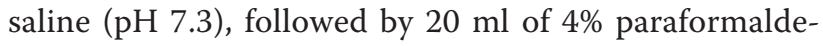
hyde or $10 \%$ neutral buffered formalin. Tissues were removed and post-fixed by submersion in 10\% formalin. Alternatively, fresh tissues were fixed by direct submersion, in $10 \%$ neutral buffered formalin, prior to processing. Tissues were processed for embedding in paraffin using an RHS Tissue Processing System (Hacker Instruments \& Industries), or processed manually. Penis tissues from 4.5-7.5 mo. old mice were cut in $5 \mu \mathrm{m}$ sections, deparaffinized, and stained with Accustain Masson Trichrome (Sigma-Aldrich) reagents, according to the manufacturer's instructions. Additionally, penis sections were stained using a polyclonal antibody against nNOS (BD Transduction Laboratories) at a 1:200 dilution, a polyclonal antibody against S100 (DAKO) at a 1:500 dilution, or a polyclonal antibody against TR4 (Santa Cruz) at a dilution of 1:200, followed by the appropriate biotinylated secondary antibody (1:1000 dilution), VECTASTAIN Elite ABC reagent (Vector Laboratories) and DAB substrate (Vector Laboratories). Hematoxylin was used as a nuclear counterstain following immunostaining.

\section{RT-PCR and Western Blot analysis of gene expression}

For RT-PCR analysis, total RNA was isolated from penis tissue using TRIzol ${ }^{\circledR}$ Reagent (Invitrogen). First strand cDNA synthesis was achieved using the Superscript ${ }^{\mathrm{TM}} \mathrm{II}$ RNase H Reverse Transcriptase kit (Invitrogen).

Real time quantitative RT-PCR was carried out, using SYBR Green PCR MasterMix, on the iCycler iQ ${ }^{\mathrm{TM}}$ PCR cycler and detection system (Bio-Rad Laboratories). Analysis of data obtained and calculation of relative gene expression was performed using the $2^{-\Delta \Delta C}{ }_{T}$ method [24]. For each gene analyzed, the expression level of the $\mathrm{TR}^{+/+}$was set at 1 and relative expression in $\mathrm{TR}_{4}{ }^{-1}$ samples was calculated. 
For Western blot analysis, total protein was isolated from penis tissue using TRIzol ${ }^{\circledR}$ Reagent (Invitrogen). A total of $75 \mu \mathrm{g}$ protein per sample was separated on either a $6 \%$ or a $10 \%$ SDS-PAGE gel. After transfer to PVDF membrane, the blots were probed with either a polyclonal antibody against nNOS (BD Transduction Laboratories) at a 1:1000 dilution, or an antibody against $\beta$-actin, followed by the appropriate alkaline phosphatase-conjugated secondary antibody at a 1:2000 dilution. Signals were detected using a chromogenic substrate.

\section{Transient transfection/reporter gene assay}

The mouse nNOS promoter plasmid pEx2 [25] was provided by Dr. Ted Dawson (Johns Hopkins University). CV1 cells were grown in Dulbecco's Modified Eagle's Medium (DMEM) with $10 \%$ fetal bovine serum, at $37^{\circ} \mathrm{C}$, and with $5 \% \mathrm{CO}_{2}$. Cells were cultured in 24-well plates (Corning) for $24 \mathrm{~h}$. Transient transfection was carried out as described previously [26]. The ß-gal activity in whole cell lysate was measured with a luminometer using a chemiluminescence-based detection system (Reaction Buffer, Galacto-Star, TROPIX) according to the manufacturer's protocol.

\section{Electrophoretic mobility shift assay (EMSA)}

TR4 proteins were synthesized in rabbit reticulocyte lysate (Promega), according to the manufacturer's instructions. The oligonucleotide probe (nNOS-NHR, bp -192 to -211, 5'-CTGGTCAACCTTGACTTCCT-3') was end-labeled with $[\gamma] 32 \mathrm{P}$ in a T4 polynucleotide kinase reaction (New England Biolabs). The EMSA assay was performed as described previously [26].

\section{Continuous mating and male sexual behavior analysis}

For the continuous mating study, $5 \mathrm{TR} 4^{+/+}$and $5 \mathrm{TR} 4^{-/-}$ males at 5 months of age were each paired with an adult $\mathrm{TR}_{4}^{+/+}$female for 4 months. The number of litters produced and the number of pups per litter were recorded. For male sexual behavior analysis, ovariectomized female mice of strain ICR, at 8-9 weeks of age, were injected with $12 \mu \mathrm{g}$ estradiol valerate one day before mating and with $500 \mu \mathrm{g}$ progesterone 4-7 hours before mating. At the time of mating, one primed female was paired with a 7-8 month-old $\mathrm{TR}_{4}^{+/+}$or TR $4^{-/-}$mouse for either $90 \mathrm{~min}$ or $6 \mathrm{~h}$, beginning between 18:00-22:00. Mating behavior was videotaped and subsequently scored for latency to, and number of mounts, intromissions, and ejaculations $[27,28]$. After the $6 \mathrm{~h}$ taped mating trial, experimental pairs remained together until the following morning. Female mice were then visually examined for the presence of a vaginal plug.

\section{Statistics}

For sexual behavior data, means and standard deviations for behavior latencies and mean number of behavior displays, with associated ranges, are shown. Extremely high variation in both latencies and numbers of specific behavioral displays was observed both within and between groups. Differences in numbers of mice of a particular genotype displaying a particular behavior were analyzed by one-tailed, independent sample $t$-tests, assuming equal variances, after coding for the presence (scored as 1) or absence (scored as 0 ) of the behavior.

\section{Results}

$\mathrm{TR}^{-/-}$males exhibit penile priapism

A physical defect observed among $\mathrm{TR} 4^{-1-}$ male mice, which may affect sexual function, is partial priapism, or persistent, partial penile erection. This condition is observed in a substantial number, but not all of the $\mathrm{TR}^{-/-}$males, and increases in prevalence with age (Figure $1 \mathrm{~A}$ and $1 \mathrm{~B})$. Once priapism was observed in a mouse, normal penile resheathing was not subsequently observed, suggesting persistence of priapism thereafter. As shown in Figure. 2, we observed more densely packed collagenous and elastic fibers in the corpus cavernosa from $\mathrm{TR} 4^{-/-}$mice with priapism, resulting in smaller cavernous sinuses, compared to $\mathrm{TR} 4^{+/+}$or $\mathrm{TR}^{-/-}$without priapism (Figure 2Cvs 2A or 2B). Our previous studies on characterization of $\mathrm{TR} 4^{-1-}$ mice found that heterozygote mice $\left(\mathrm{TR}_{4}^{+/-}\right)$are indistinguishable with $\mathrm{TR} 4^{+/+}$mice [11], and this remains true in this current study that $\mathrm{TR} 4^{+/-}$, like $\mathrm{TR} 4^{+/+}$, have no obvious defects. Therefore, we used $\mathrm{TR} 4^{+/+}$as a control group in following studies. TR4 Comparing histological sections of penis tissue from a TR $4^{+/+}$mouse (no priapism), a TR $4^{-1-}$ mouse without priapism, and a TR $4^{-1-}$ mouse with priapism (Figure 2D-L), we found more red blood cells within the corpus cavernosa (CC), and corpus spongiosum $(\mathrm{CS})(\mathrm{H} \& \mathrm{I}$ vs $\mathrm{G}$ ) and dorsal vein (DV) ( $\mathrm{K} \& \mathrm{~L}$ vs J) in $\mathrm{TR}^{-/-}$tissue than in $\mathrm{TR} 4^{+/+}$tissue.

\section{Regulation of nNOS transcriptional activation by TR4}

To uncover TR4 roles in controlling penile activity, TR4 expression profiles were determined by the immunostaining of cross sectioned penis tissue. We observed TR4 expression in smooth muscle surrounding the penile vasculature (Additional File 1 Figure S1), a region where nNOS is also expressed [29]. A neuronal marker, S100, was used to confirm the dorsal nerve bundles in all sections. The penile erection requires NO released in the penis upon sexual stimulation. The synthetic enzyme for production of $\mathrm{NO}$, a signaling molecule that is known to play a role in regulation of penile erection $[30,31]$, was assayed in penis tissue. Through immunostaining for nNOS, we confirmed the colocalization of TR4 and nNOS in smooth muscle surrounding the penile vasculature, but also found significant variation in expression of nNOS, even within the same tissue 


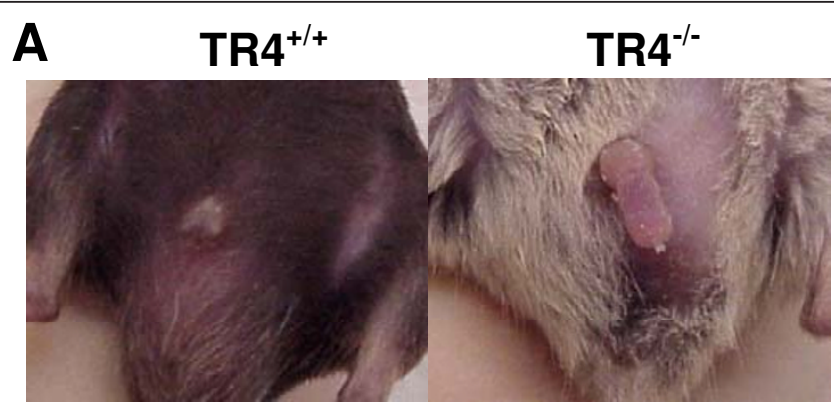

B

\begin{tabular}{cccc}
\hline Age & $\begin{array}{c}\text { Total } \\
\text { TR4 }^{-/-}\end{array}$ & $\begin{array}{c}\text { TR4 }^{-/-} \text {with } \\
\text { priapism }\end{array}$ & $\begin{array}{c}\% \text { with } \\
\text { priapism }\end{array}$ \\
\hline 6-12 wks & 27 & 6 & 22.2 \\
13-24 wks & 19 & 7 & 36.8 \\
7-12 mo. & 17 & 11 & 64.7
\end{tabular}

Figure 1 TR4 ${ }^{-/-}$males display priapism. A. TR4 ${ }^{+/+}$male (left), and TR4 $4^{-/-}$male (right) showing priapism; both mice were 7 mo. old. B. Number and percentage of $\mathrm{TR}^{-/-}$mice showing priapism at various ages.

(Additional File 1 Figure S1). To further quantify nNOS expression, quantitative real time RT-PCR with RNA from 7-month-old male $\mathrm{TR}^{-1-}$ mice was used, and nNOS was found to be reduced by more than $65 \%$ relative to $\mathrm{TR} 4^{+/+}$levels (Figure $3 \mathrm{~A}$ ). In addition to $\mathrm{nNOS}$, we also found a significant reduction of mRNA expression of eNOS gene, another important NOS in regulating erection in $\mathrm{TR} 4^{-/-}$(data not shown). Western blot analysis showed a clear reduction in the amount of nNOS protein present in TR $4^{-1-}$ mouse penis tissue (Figure $3 \mathrm{~B})$. As a transcriptional factor, TR4 often regulates gene expression via binding to TR4 responsive element (TR4RE). Via sequence searching, a putative TR4RE was found in nNOS promoter. A reporter assay demonstrated that transfection of TR4 could enhance nNOS reporter gene expression (Figure 3C). The nNOS exon 2 contains a nuclear hormone receptor response element (NHR) through which the nuclear receptor SF-1 was found to bind and modulate nNOS transcription [25]. Using the EMSA assay, we demonstrated that TR4 protein can bind to the mouse nNOS NHR sequence (Figure 3D lane 2, TR4/nNOS-NHR), and this specific TR4NHR complex can be super-shifted by addition of a TR4-specific antibody (lane 3, TR4/nNOS-NHR/Ab). In summary, we identified TR4 as a key modulator to control the penile function via a transcriptional regulation of nNOS expression, and loss of TR4 resulted in reduced nNOS expression that might contribute to penile priapism. TR4 represents a novel regulator that modulates nNOS gene expression to regulate penile function.
Reduced fertility and aberrant sexual behavior in male $\mathrm{TR}^{-/-}$mice

Five adult $\mathrm{TR} 4^{+/+}$males were mated with sexually mature female mice, producing a total of 22 litters. An average of 4.4 litters were produced per $\mathrm{TR} 4^{+/+}$mouse in 4 months (Table 1). In contrast, only one of the 5 $\mathrm{TR}^{-/-}$males produced offspring, with a total of two litters born during the 4 month period (Table 1). Not only were significantly fewer $\mathrm{TR} 4^{-1-}$ males able to produce offspring, the number of litters generated by the known fertile $\mathrm{TR}^{-1-}$ male was approximately half that of the $\mathrm{TR}_{4}^{+/+}$average (Table 1$)$.

The initial male sexual behavior analysis that was carried out (Table 2 Trial 1) demonstrated defects in $\mathrm{TR}^{-1-}$ sexual behavior, as well as social behavior. It was found that naïve $\mathrm{TR} 4^{-1-}$ mice do not show defined sexual behavior within 90 minutes of the initial pairing with a primed female mouse. Out of $9 \mathrm{TR} 4^{+/+}$mice tested for sexual behavior, all 9 showed mounting behavior, 5 displayed intromission, and two achieved ejaculation, whereas none of the same behaviors were observed among the $11 \mathrm{TR} 4^{-/-}$mice tested (Table 2). Interestingly, the $\mathrm{TR} 4^{-1-}$ mice displayed fear or anxiety in the presence of a hormonally primed female, with a delay in showing interaction with the potential mate. In the most severe cases, the $\mathrm{TR}_{4}{ }^{-1-}$ male spent the entire test session actively avoiding his cage mate.

Given extended pairing time, up to $6 \mathrm{~h}$ (Trial 2), $\mathrm{TR}^{-/-}$mice did begin to display sexual behavior. Again, proportionally fewer $\mathrm{TR} 4^{-/-}$than $\mathrm{TR} 4^{+/+}$mice displayed each defined sexual behavior, with increased latencies to 


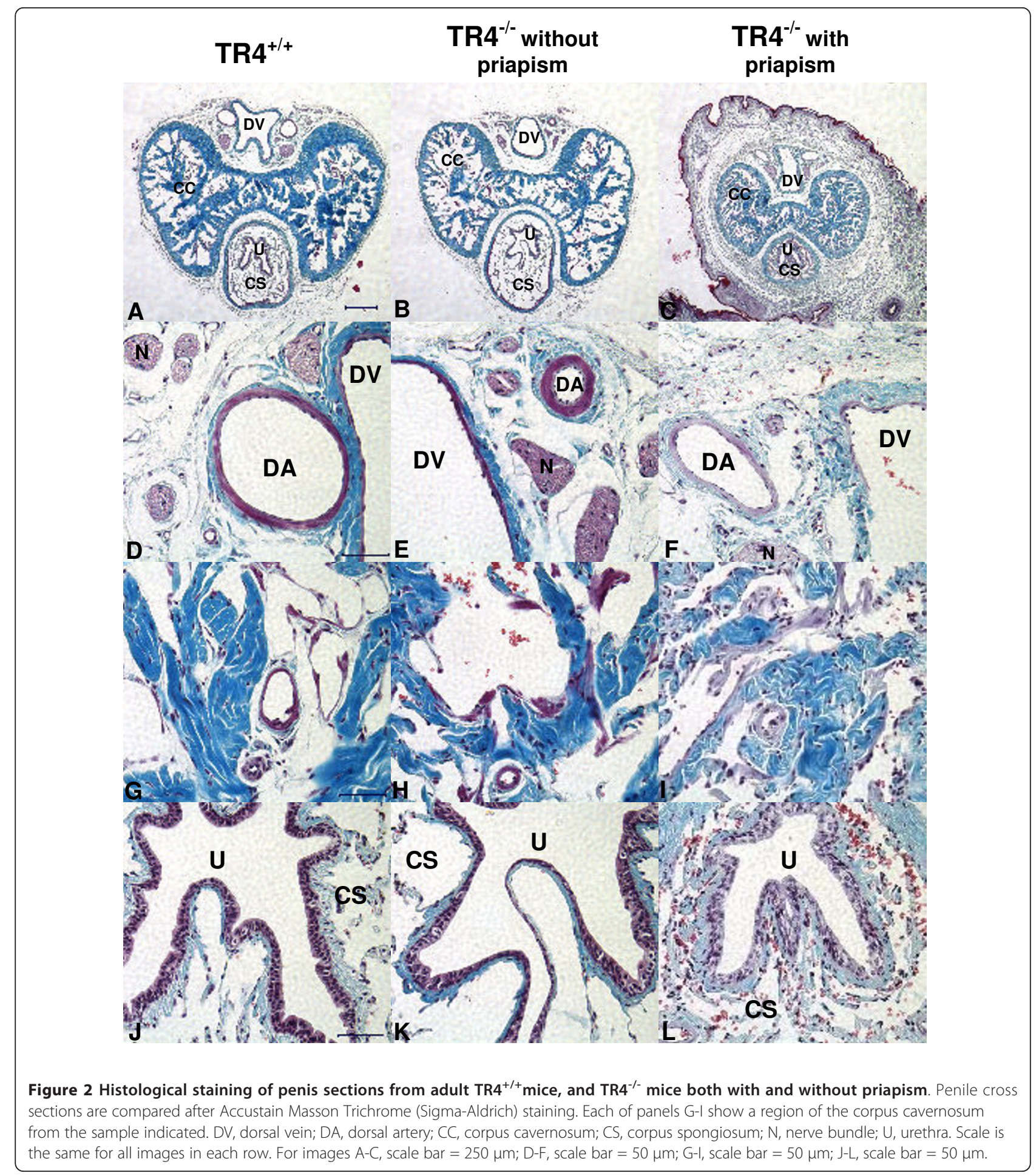

each behavior in $\mathrm{TR}^{-1-}$ males (Table 2). After the videotaped $6 \mathrm{~h}$ pairing, male and female mice were left paired, and female mice were examined for vaginal plugs the following morning. Vaginal plugs were discovered in each of the female mice paired with $\mathrm{TR} 4^{+/+}$ males, whereas none of the females paired with $\mathrm{TR} 4^{-1-}$ males had plugs (Table 2).

Expression levels of several genes known to affect behavior, particularly sexual behavior, were determined via semi-quantitative RT-PCR and quantitative real time 

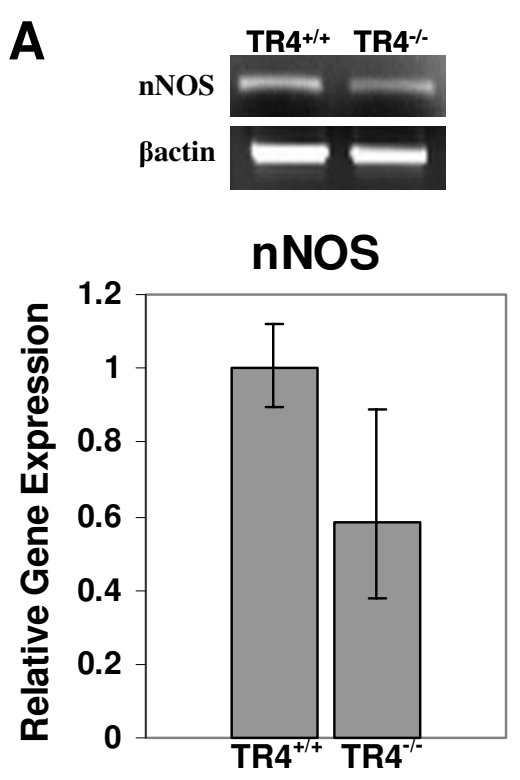

B

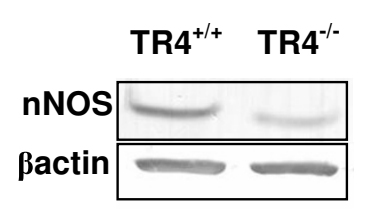

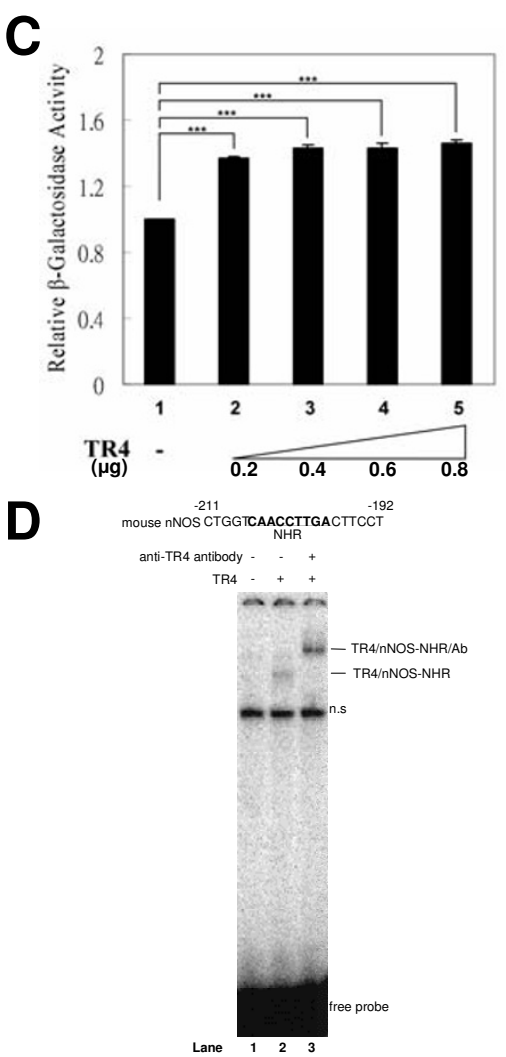

Figure 3 Expression of nNOS is reduced in the TR4 ${ }^{-/-}$penis, and TR4 binds and activates the nNOS promoter. A. Qualitative RT-PCR (upper panel) and real time RT-PCR quantitation (lower panel) of nNOS gene expression in the penis. Expression data were obtained, in triplicate, from each of two TR4 ${ }^{+/+}$and two TR4 ${ }^{-/}$mice. $\beta$-actin levels were determined as a control for template amount in PCR reactions. $\mathbf{B}$. Western blot analysis of penis samples from TR4 ${ }^{+/+}$and TR4 ${ }^{-/-}$mice (with priapism) demonstrates reduced nNOS protein expression in TR4 ${ }^{-1}$ tissue. Samples from each of $3 \mathrm{TR}^{+/+}$and $3 \mathrm{TR}^{-/-}$mice were analyzed, and a representative blot is shown. C. Transactivation assay for TR4 regulation of nNOS expression. TR4 can activate the nNOS exon 2 promoter and control basal nNOS transcription. pEx2 (0.2 $\mu \mathrm{g})$ and increasing amounts of TR4 were cotransfected into CV-1 cells. Promoter activity of each sample was normalized to the average activity of the pEx2 promoter when transfected alone. Results are the mean \pm SEM from at least three experiments performed in duplicate. ${ }^{* * *}<<0.01 \mathrm{~d}$. By EMSA assay, TR4 is shown to bind to the nNOS-NHR probe (TR4/nNOS-NHR). The presence of TR4 in the complex was confirmed by supershift (TR4/ nNOS-NHR/Ab) using a TR4-specific antibody. n.S., nonspecific binding.

PCR, using hypothalamic tissue from $\mathrm{TR} 4^{-/-}$and $\mathrm{TR} 4^{+/+}$ mice. RT-PCR results demonstrate that hypothalamic expression of estrogen receptor (ER) alpha $(\alpha)$, ER beta $(\beta)$, and oxytocin is reduced in $\mathrm{TR} 4^{-/-}$mice (Additional File 2 Figure S2). No differences in levels of the androgen receptor (AR) or vasopressin (VP) were apparent. After quantitative real time PCR analysis, it was clear

Table 1 Fertility rates of 5 month old $\mathrm{TR4}^{+/+}$and $\mathrm{TRH}^{-/-}$ males

\begin{tabular}{lcccc}
\hline TR4 genotype & \multicolumn{2}{c}{ Litters } & \multicolumn{2}{c}{ Offspring } \\
& total & per male & total & per litter \\
\hline$+/+(\mathrm{N}=5)$ & 22 & 4.4 & 168 & 7.6 \\
$-/(\mathrm{N}=5)$ & 2 & $\mathrm{NA}$ & 13 & 6.5 \\
\hline
\end{tabular}

Continuous mating with $\mathrm{TR}^{+/+}$females for 4 month NA, not applicable since only one male produced offspring in the $\mathrm{TR}^{-/-}$group. that the levels of ER $\alpha, E R \beta$, and oxytocin were reduced by approximately $50-60 \%$ in the hypothalamic region of $\mathrm{TR}^{-/-}$mice compared to TR4 ${ }^{+/+}$(Additional File 2 Figure S2). More detailed mechanism dissection as to how TR4 regulates the expression of those genes involved in the sexual behavior and consequently affects reproductive function need further investigation.

\section{Discussion}

In addition to the inability of the $\mathrm{TR} 4^{-/-}$mice with priapism to retract the penis back within the sheath (Figure 1A), histological evidence of priapism was observed (Figure 2). Trapped blood within the corpus cavernosum of the penis leads to pathology resulting from reduced tissue oxygenation and, without treatment, could result in permanent erectile dysfunction $[21,22,32]$. Compared with $\mathrm{TR} 4^{+/+}$mice, both $\mathrm{TR} 4^{-/-}$ 
Table 2 Male sexual behavior

\begin{tabular}{|c|c|c|c|c|}
\hline \multirow[t]{2}{*}{ Behavior } & \multicolumn{2}{|c|}{ TRIAL, $90 \mathrm{~min}$} & \multicolumn{2}{|c|}{ TRIAL, $6 \mathrm{~h}$} \\
\hline & $\mathrm{TR}^{+/+}(\mathrm{N}=9)$ & $\mathrm{TR}^{-1-}(\mathrm{N}=11)$ & $\mathrm{TR}^{+/+}(\mathrm{N}=4)$ & $\mathrm{TR}^{-/-}(\mathrm{N}=6)$ \\
\hline \multicolumn{5}{|l|}{ Mounts } \\
\hline No. of mice & $9 / 9^{+}$ & $0 / 11^{*}$ & $4 / 4^{+}$ & $5 / 6$ \\
\hline Mean no. of mounts & & 0 & & 33.8 \\
\hline Range & $3-70$ & & $11-24$ & $0-58$ \\
\hline Latency to behavior ${ }^{++}$ & & & $21.5 \pm 20.0$ & $136.8 \pm 111.1^{*}$ \\
\hline \multicolumn{5}{|l|}{ Intromissions } \\
\hline No. of mice & $5 / 9$ & $0 / 11^{*}$ & $4 / 4$ & $2 / 6$ \\
\hline Mean no. of mounts & & 0 & 14 & 7.2 \\
\hline Range & $0-98$ & & $11-17$ & $0-34$ \\
\hline Latency to behavior ${ }^{++}$ & & & $44.3 \pm 32.1$ & $89.8 \pm 89.5$ \\
\hline \multicolumn{5}{|l|}{ Ejaculation } \\
\hline No. of mice & $2 / 9$ & $0 / 11^{*}$ & $4 / 4$ & $1 / 6^{*}$ \\
\hline Latency to behavior ${ }^{++}$ & & & $71.2 \pm 58.6$ & 91 \\
\hline Plug Present & & & $4 / 4$ & $0 / 6$ \\
\hline
\end{tabular}

${ }^{+}$Number of mice showing behavior/number of mice tested; ${ }^{++}$Mean \pm standard deviation among animals showing behavior; Latencies are reported in minutes; ${ }^{*} \mathrm{P}<0.05$

animals with and without priapism have increased presence of red blood cells observed in penile cross section, with the largest amount present in sections of penis tissue from TR4 ${ }^{-1-}$ mice with priapism (Figure 2L). Histology also revealed more densely packed tissue in the $\mathrm{TR}^{-/-}$mice with priapism, compared with $\mathrm{TR} 4^{+/+}$mice and $\mathrm{TR} 4^{-/-}$mice without priapism, suggesting loss of elasticity of the normally flexible penile structures (e.g. corpus cavernosum, corpus spongiosum) (Figure 2C).

The neurotransmitter $\mathrm{NO}$ is a known mediator of erectile function that promotes vasodilation and the inflow of blood, resulting in penile tumescence [33]. nNOS is an enzyme responsible for production of $\mathrm{NO}$ in the penis [34], and expression of both nNOS mRNA and protein were reduced in the $\mathrm{TR} 4^{-/-}$mouse penis (Figure 3A and 3B). It was also found that TR4 is able to bind the NHR of exon 2 (Figure 3D), as well as upregulate nNOS gene expression in a reporter gene assay (Figure $3 \mathrm{C}$ ). Immunostaining of penis tissue for TR4 and nNOS resulted in localization of both proteins in smooth muscle surrounding penile vasculature, further implicating TR4 in the regulation of vascular function via nNOS. As reported by Champion that NOS mutant mice: $\mathrm{eNOS}^{-/-}$and $\mathrm{eNOS}^{-/-}, \mathrm{nNOS}^{-/-}$displayed priapism where the expression of phosphodiesterase type 5 expression (PDE5A) was reduced, and transfection of eNOS normalized PDE5A expression and corrected priapic activity and there is less impact on loss of nNOS [23]. Therefore, in addition to nNOS, we also checked the expression of eNOS and PED5A in $\mathrm{TR} 4^{-1-}$ penis, and found no significant difference from $\mathrm{TR}^{+/+}$(data not shown). These results suggest that erectile function may be negatively affected by the loss of TR4 function in $\mathrm{TR} 4^{-/-}$mice, with or without priapism.

In addition to the possible loss of erectile function in $\mathrm{TR}^{-/-}$mice via reduced nNOS expression and/or resulting from the development of priapism, as well as the detrimental effects of loss of TR4 on male germ cell development [20], abnormal sexual behavior is a significant contributor to the reduced fertility of male $\mathrm{TR} 4^{-/-}$ mice. For each sexual behavior demonstrated by $\mathrm{TR} 4^{-1-}$ mice, the latency to behavioral display was increased compared to $\mathrm{TR}^{+/+}$(Table 2). These results indicate that $\mathrm{TR} 4^{-1-}$ mice still retain sexual motivation, yet take longer to become acclimated to the pairing situation and begin showing sexual behaviors. Furthermore, $\mathrm{TR}^{-1-}$ males are less successful in achieving ejaculation. In fact, a large proportion of TR $4^{-1-}$ males tested for $6 \mathrm{~h}$ did not even achieve intromission. From observation of the $\mathrm{TR} 4^{-1-}$ mice during the mating trials, it became evident that they had difficulty in maintaining the appropriate mounting position through which intromission and ejaculation could be achieved.

TR4 ubiquitously expresses in almost all the tissues we examined, with high abundance in testis, and that leads to our first discovery of TR4 roles in male fertility via controlling spermatogenesis [20]. This current study further extends TR4's role as a master regulator in male fertility via controlling both sexual/social behavior and internal physiological events. This discovery points to the development of novel strategies for male fertility therapy that specifically target TR4. We have identified that polyunsaturated fatty acid could potentiate TR4 activity to control the lipid metabolism [19], and it will be of great interest to identify TR4 upstream modulators 
that can promote TR4 activity in male reproductive organs.

\section{Conclusions}

Collectively, the data reported here describe severe reproductive malfunctions in $\mathrm{TR} 4^{-/-}$male mice, with significant effects stemming from abnormal sexual behavior, as $\mathrm{TR}^{-1-}$ mice rarely achieve intromission or ejaculation. In $\mathrm{TR} 4^{-/-}$mice with priapism, erectile function may eventually be lost due to loss of collagenous tissue elasticity in the corpora cavernosa and corpus spongiosum, and account for the lack of intromission or ejaculation. In $\mathrm{TR} 4^{-1-}$ males with or without priapism, disruptions of signaling pathways involving nNOS (Figures 3 and Additional File 1 Figure S1) may also affect erectile function. These in vivo data demonstrate that TR4 plays an important part in various aspects of reproduction and behavior, and future studies to more finely dissect the roles of TR4 in penile physiology and in brain/behavioral function may lead to identification of additional TR4 target genes, greater knowledge of the involvement of the receptor in various signaling pathways, or the discovery of new physiological ligand for TR4.

\section{Additional material}

Additional file 1: Supplemental Figure S1. Localization of both TR4 and nNOS to vascular smooth muscle in the mouse penis. Penis sections from adult TR4 ${ }^{++}$and $\mathrm{TR}_{4}^{-{ }^{--}}$(both with and without priapism) mice were stained for neuronal nitric oxide synthase (nNOS), the neuronal marker S100, or TR4 protein, as indicated. Immunoreactivity for both nNOS (upper panels) and TR4 (lower panels) was found in the smooth muscle surrounding veins (DV, dorsal vein) and arteries (DA, dorsal artery), as well as venules $(V)$ and arterioles (A), of the penis. TR4 immunoreactivity is shown in an arteriole of the corpus cavernosum of a TR4 ${ }^{+/+}$mouse, whereas no immunoreactivity was observed in the same structures from $\mathrm{TR}^{-/-}$mice. $\mathrm{S} 100$ immunoreactivity was observed in dorsal nerve bundles in all sections probed for the protein. CC, corpus cavernosum; CS, corpus spongiosum.

Additional file 2: Supplemental Figure S2. RT-PCR and real time PCR analysis of sexual behavior/function-related gene expressions in the hypothalamus. A. Qualitative RT-PCR analysis of AR, ER $\alpha$, ER $\beta, V P$, and OT mRNA expression. $\beta$-actin levels were determined as a control for template amount in PCR reactions. B. Real time PCR quantitation of those genes expressing in the hypothalami of $\mathrm{TR}^{+/+}$and $\mathrm{TR} 4^{-/-}$mice. Relative gene expression levels are shown. For both RT-PCR and real-time RT-PCR analyses, triplicate data from each of three $\mathrm{TR}^{+/+}$and three $\mathrm{TR}^{-/}$mice were obtained.

\section{Abbreviations}

TR4: testicular orphan nuclear receptor 4; NOS: nitric oxide synthase; RT-PCR: reverse transcription-polymerase chain reaction; NHR: nuclear hormone receptor response element.

\section{Acknowledgements}

This work was supported by NIH (DK063212 and CA127548). Taiwan Department of Health Clinical Trial and Research Center of Excellence grant DOH99-TD-B- 111-004 (China Medical University, Taichung, Taiwan).

\section{Author details}

'George Whipple Lab for Cancer Research, Departments of Pathology, Urology, Radiation Oncology, and The Cancer Center, University of Rochester Medical Center, Rochester, NY 14642, USA. ${ }^{2}$ Research Services, V.A. Medical Center and Department of Behavioral Neuroscience, Oregon Health \& Science University, Portland, OR 97239, USA. ${ }^{3}$ Wisconsin Regional Primate Research Center, University of Wisconsin, Madison, WI 53708, USA. ${ }^{4}$ Sex Hormone Research Center and School of Pharmacy, China Medical University, Taichung, Taiwan. ${ }^{5}$ Department of Urology, Chang Gung University, Kaohsiung 833, Taiwan.

\section{Authors' contributions}

LC, YFL carried out the TR4 $4^{-/}$mice sexual behavior experiments and characterized penile priapsim phenotype and wrote the manuscript. HJT and BYB carried out eNOS and nNOS expression in gene and protein levels, WJL and YTC participated in sexual behavior experiments. NCL carried out nNOS reporter gene assay. CKM, HU and CC participated in its design and coordination and helped to draft the manuscript. All authors read and approved the final manuscript.

\section{Competing interests}

The authors declare that they have no competing interests.

Received: 27 June 2011 Accepted: 13 October 2011

Published: 13 October 2011

\section{References}

1. Evans RM: The steroid and thyroid hormone receptor superfamily. Science 1988, 240:889-895

2. Lee YF, Lee HJ, Chang C: Recent advances in the TR2 and TR4 orphan receptors of the nuclear receptor superfamily. Journal of Steroid Biochemistry \& Molecular Biology 2002, 81:291-308.

3. Qiu Y, Pereira FA, DeMayo FJ, Lydon JP, Tsai SY, Tsai MJ: Null mutation of mCOUP-TFI results in defects in morphogenesis of the glossopharyngeal ganglion, axonal projection, and arborization. Genes Dev 1997, 11:1925-1937.

4. Shyr C, Collins LL, Mu X, Platt KA, Chang C: Spermatogenesis and testis development are normal in mice lacking testicular orphan nuclear receptor 2. Mol Cell Biol 2002, 22:4661-4666

5. Young WJ, Smith SM, Chang C: Induction of the intronic enhancer of the human ciliary neurotrophic factor receptor (CNTFRa) gene by the TR4 orphan receptor. J Biol Chem 1997, 272:3109-3116.

6. Young WJ, Lee YF, Smith SM, Chang C: A bidirectional regulation between the TR2/TR4 orphan receptors (TR2/TR4) and the ciliary neurotrophic factor (CNTF) signaling pathway. J Biol Chem 1998, 273:20877-20885.

7. Lee YF, Young WJ, Burbach JPH, Chang C: Negative feedback control of the retinoid-retinoic acid/retinoid $\times$ receptor pathway by the human TR4 orphan receptor, a member of the steroid receptor superfamily. J Biol Chem 1998, 273:13437-13443.

8. Lee $\mathrm{CH}$, Chinpaisal $\mathrm{C}$, Wei LN: A novel nuclear receptor heterodimerization pathway mediated by orphan receptors TR2 and TR4. Journal of Biological Chemistry 1998, 273:25209-25215.

9. Chang C, Da Silva SL, Ideta R, Lee YF, Yeh S, Burbach JPH: Human and rat TR4 orphan receptors specify a subclass of the steroid receptor superfamily. Proceedings of the National Academy of Sciences USA 1994, 1994:6040-6044.

10. van Schaick HSA, Rosmalen JGM, Lopes da Silva S, Chang C, Burbach JPH: Expression of the orphan receptor TR4 during brain development of the rat. Molecular Brain Research 2000, 77:104-110.

11. Collins LL, Lee YF, Heinlein CA, Liu NC, Chen YT, Shyr CR, Meshul CK, Uno H, Platt KA, Chang C: Growth retardation and abnormal maternal behavior in mice lacking testicular orphan nuclear receptor 4. Proc Natl Acad Sci USA 2004, 101:15058-15063.

12. Chen LM, Wang RS, Lee YF, Liu NC, Chang YJ, Wu CC, Xie S, Hung YC, Chang C: Subfertility with defective folliculogenesis in female mice lacking testicular orphan nuclear receptor 4. Mol Endocrinol 2008, 22:858-867.

13. Chen $Y T$, Collins $L L$, Uno $H$, Chang C: Deficits in motor coordination with aberrant cerebellar development in mice lacking testicular orphan nuclear receptor 4. Molecular \& Cellular Biology 2005, 25:2722-2732. 
14. Chen YT, Collins LL, Chang SS, Chang C: The roles of testicular orphan nuclear receptor 4 (TR4) in cerebellar development. Cerebellum 2008, 7:9-17.

15. Zhang Y, Chen YT, Xie S, Wang L, Lee YF, Chang SS, Chang C: Loss of testicular orphan receptor 4 impairs normal myelination in mouse forebrain. Mol Endocrinol 2007, 21:908-920.

16. Liu NC, Lin WJ, Kim E, Collins LL, Lin HY, Yu IC, Sparks JD, Chen LM, Lee YF, Chang C: Loss of TR4 orphan nuclear receptor reduces phosphoenolpyruvate carboxykinase-mediated gluconeogenesis. Diabetes 2007, 56:2901-2909.

17. Kim E, Liu NC, Yu IC, Lin HY, Lee YF, Sparks JD, Chen LM, Chang C: Metformin inhibits nuclear receptor TR4-mediated hepatic stearoyl-CoA desaturase 1 gene expression with altered insulin sensitivity. Diabetes 60:1493-1503.

18. Kang HS, Okamoto K, Kim YS, Takeda Y, Bortner CD, Dang H, Wada T, Xie W, Yang XP, Liao G, Jetten AM: Nuclear orphan receptor TAK1/TR4deficient mice are protected against obesity-linked inflammation hepatic steatosis, and insulin resistance. Diabetes 60:177-188.

19. Xie S, Lee YF, Kim E, Chen LM, Ni J, Fang LY, Liu S, Lin SJ, Abe J, Berk B, et al: TR4 nuclear receptor functions as a fatty acid sensor to modulate CD36 expression and foam cell formation. Proceedings of the National Academy of Sciences of the United States of America 2009, 106:13353-13358.

20. Mu X, Lee Y, Liu N, Chen Y, Kim E, Shyr C, Chang C: Targeted inactivation of Testicular nuclear Orphan Receptor 4 delays and disrupts late meiotic prophase and subsequent meiotic divisions of spermatogenesis. Mol Cell Biochem 2004, 24:5887-5899.

21. Hauri D, Spycher M, Bruhlmann W: Erection and priapism: A new physiopathological concept. Urol Int 1983, 88:138-145.

22. Panteleo-Gandais $\mathrm{M}$, Chalbaud $\mathrm{R}$, Chacon O, Plaza N: Priapism: evaluation and treatment. Urology 1984, 24:345-346.

23. Champion HC, Bivalacqua TJ, Takimoto E, Kass DA, Burnett AL: Phosphodiesterase-5A dysregulation in penile erectile tissue is a mechanism of priapism. Proceedings of the National Academy of Sciences of the United States of America 2005, 102:1661-1666.

24. Livak KJ, Schmittgen TD: Analysis of relative gene expression data using real-time quantitative PCR and the $2^{-\mathrm{DDC}}$ T method. Methods 2001, 25:402-408.

25. Wei $X$, Sasaki M, Huang H, Dawson VL, Dawson TM: The orphan nuclear receptor, Steroidogenic Factor 1, regulates neuronal Nitric Oxide Synthase gene expression in pituitary gonadotropes. Mol Endocrinol 2002, $16: 2828-2839$

26. Lee YF, Pan HJ, Burbach PH, Morkin E, Chang C: Identification of direct repeat 4 as a positive regulatory element for the human TR4 orphan receptor: a modulator for the thyroid hormone target genes. J Biol Chem 1997, 272:12215-12220

27. Kriegsfeld L, Demas GE, Huang PL, Burnett AL, Nelson RJ: Ejaculatory abnormalities in mice lacking the gene for endothelial nitric oxide synthase (eNOS-/-). Physiol Behav 1999, 67:561-566.

28. Ogawa S, Chan J, Chester AE, Gustafsson J, Korach KS, Pfaff DW: Survival of reproductive behaviors in estrogen receptor b gene-deficient (bERKO) male and female mice. Proc Natl Acad Sci USA 1999, 96:12887-12892.

29. Segal SS, Brett SE, Sessa WC: Codistribution of NOS and caveolin throughout peripheral vasculature and skeletal muscle of hamsters. Am J Physiol 1999, 277:H1167-H1177.

30. Rampin O, Guiliano F: Brain control of penile erection. World J Urol 2001, 19:1-8.

31. Steers WD: Neural pathways and central sites involved in penile erection: neuroanatomy and clinical implications. Neurosci Biobehav Rev 2000, 24:507-516.

32. Winter CC: Priapism. Urological Surgery 1978, 28:163.

33. Burnett AL: Nitric oxide in the penis: physiology and pathology. I Urol 1995, 157:320-324

34. Yun HY, Dawson VL, Dawson TM: Neurobiology of nitric oxide. Crit Rev Neurobiol 1996, 10:291-316.

doi:10.1186/1477-7827-9-138

Cite this article as: Collins et al:: The roles of testicular nuclear receptor 4 (TR4) in male fertility-priapism and sexual behavior defects in TR4 knockout mice. Reproductive Biology and Endocrinology 2011 9:138.

\section{Submit your next manuscript to BioMed Central and take full advantage of:}

- Convenient online submission

- Thorough peer review

- No space constraints or color figure charges

- Immediate publication on acceptance

- Inclusion in PubMed, CAS, Scopus and Google Scholar

- Research which is freely available for redistribution

Submit your manuscript at www.biomedcentral.com/submit
Biomed Central 